DOI: 10.20472/IAC.2018.040.029

\title{
SAKAUWRAT JONGPATTANAKORN
}

Kasertsart University, Thailand

\section{INFORMATION TECHNOLOGY PROJECT WITH AUGMENTED REALITY}

\begin{abstract}
:
This research aimed to study and design information technology project with Augmented Reality for learning and teaching. It was a case study. The sample group was 8 students who studied the special problem course and 20 users were used to evaluate the systems. The methods of data collection were questionnaires and information technology projects. The key performance indicators in this study included 8 information technology systems, usability of system, the accuracy and completeness of system. The instruments used in this study were: time to develop information system and evaluate users' document. The data were analyzed by mean and standard deviation. The results of this research found that 6 information technology systems submitted in time and 2 information technology systems had been delayed for one month. For the system evaluation, it was found that the mean score of systems acceptance was 4.25 and the standard deviation was 0.15 . The students and users expressed positive attitudes towards instruments of learning and information technology systems.
\end{abstract}

\section{Keywords:}

Information Technology Project, AR, Augmented Reality Project

JEL Classification: 129, 032, C63 


\section{Introduction}

At present, information technology has been applied to use in learning and teaching. Information technology has been developed to use in business transaction, commercial, mobile device and artificial intelligent system. The systems development cycle should be followed in the design of systems and interfaces to ensure they are effective and efficient. It is, however, not an easy task to analysis and design the new system to accept by user (Kendal, 2005). Based on a special problem course in the Information Technology Program of the Faculty of Liberal Arts and Sciences, students are required to take a requisite course to do the information technology system project before examination. In order to develop our learning and teaching to be up to date, information technology with augmented reality has been applied to use research project.

\section{Method}

The case study used research and development method.

\section{Sample Group}

The sample group consists of 8 students studying special problem course in the academic year 2017 on Information Technology program at Kasetsart University, Khamphensan campus and 20 users were used to evaluate the systems.

The procedures conducting this study were as follows:

1. Week 1, the researcher designed the content and activities for the students including instruments used to develop information system, computer language and evaluate systems' document.

2. Week 2, there were 8 new systems for the students to choose to develop information technology project with augmented reality.

3. Week 3 , the researcher interviewed 8 students to evaluate the suitability of each system.

4. The students studied the new systems and wrote the information requirement to serve the users' needs.

5. The sample group was 8 students who studied the special problem course and 20 users evaluated the new systems.

6. Students started their project in Week 4 and completed it in Week 15.

7. Students submitted their sub-system to the teacher every two weeks.

8. Week 13, each student presented his/her information system reports to class within 20 minutes.

9. Week 14, 20 users used and accepted testing information technology systems.

10. Week 15, the final version of information technology project with augmented reality was submitted to the teacher. 


\section{Results}

The results of this research were as follows:

Students submitted the activities to the teacher in time as shown in Table 1

Table 1: 8 students submitted the activities in time

\begin{tabular}{|l|c|c|}
\hline Topics & \multicolumn{2}{|c|}{ Level score (100 \%) } \\
\hline & Complete & Modify \\
\hline Proposal Project & 87.5 & 12.5 \\
\hline Requirement & 75.0 & 25.0 \\
\hline Use case diagram & 87.5 & 12.5 \\
\hline Sub System & 50.0 & 50.0 \\
\hline Testing & 62.5 & 37.5 \\
\hline Reports & 75.0 & 25.0 \\
\hline
\end{tabular}

Source : Own data

Table 1 showed that there were 6 activities in this study : proposal project, requirement, use case diagram, sub system, testing and reports. The students got the highest level score in proposal project and use case diagram activities. The level score of sub-system activity needs to modify the most.

Table 2 : Information Technology Project with Augmented Reality

\begin{tabular}{|l|c|}
\hline \multicolumn{1}{|c|}{ System type } & Project \\
\hline Faculty and Location & 2 \\
\hline Learning Buildings & 2 \\
\hline Physical Education Building & 1 \\
\hline Tourist Attraction & 2 \\
\hline Dormitory & 1 \\
\hline
\end{tabular}

Source : Own data

Table 2 showed that the projects can be divided into 2 main types : buildings projects and facilities projects. Faculty and location, learning buildings and physical education building systems are building projects while tourist attraction and dormitory systems are facilities projects. 
Table 3 Information System Evaluation by Teacher

\begin{tabular}{|l|c|c|}
\hline \multirow{2}{*}{ Detail of Evaluation } & \multicolumn{2}{|c|}{ Quality } \\
\cline { 2 - 3 } & Complete & Modify \\
\hline Usability of system & 6 & 2 \\
\hline Accuracy & 8 & - \\
\hline Efficiency & 5 & 3 \\
\hline Completeness & 7 & 1 \\
\hline Functionality & 7 & 1 \\
\hline Submitted project in time & 6 & 2 \\
\hline
\end{tabular}

Source : Own data

Table 3 showed that the criteria used to evaluate the accuracy, usability of system and submission were in time. The evaluation of information technology systems by teacher were : usability, accuracy, efficiency, completeness functionality and submitted project in time. 6 information systems (75\%) submitted in time and 2 information systems (25\%) had been delayed for one month..

Table 4 : System Evaluation by 20 Users

\begin{tabular}{|c|c|c|c|}
\hline \multicolumn{2}{|r|}{ Content Validity } & $\bar{x}$ & SD \\
\hline 1 & Usability of System & 4.20 & 0.15 \\
\hline 2 & Functionality & 4.35 & 0.10 \\
\hline 3 & Satisfactory & 4.15 & 0.22 \\
\hline 4 & User Interface & 4.30 & 0.12 \\
\hline & Average & 4.25 & 0.15 \\
\hline
\end{tabular}

Source : Own data

Table 4, the results revealed that the sample groups were satisfied with this content validity of system at a high level and the mean score was 4.25 and the standard deviation of users' satisfaction was 0.15 . 
Figure 1 Information Technology project with augmented reality model

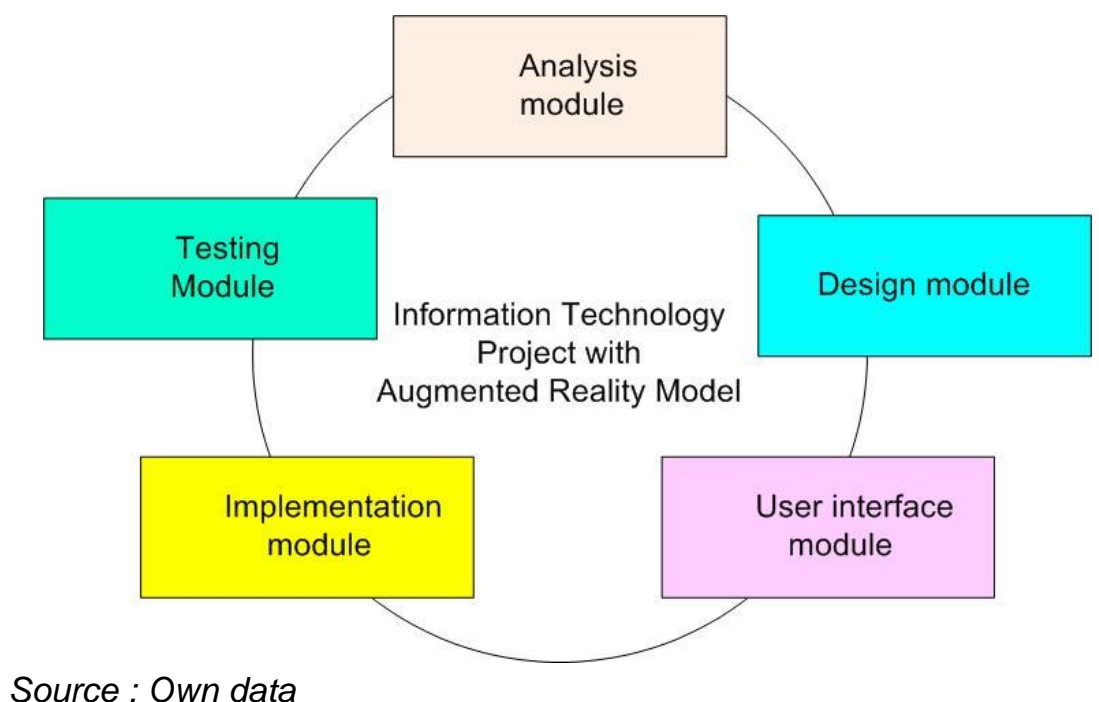

The results from figure 1, information technology project with augmented reality model included 5 components: analysis module, design module, user interface module, implementation module and testing module.

Figure 2 Information Technology project with augmented reality for learning building

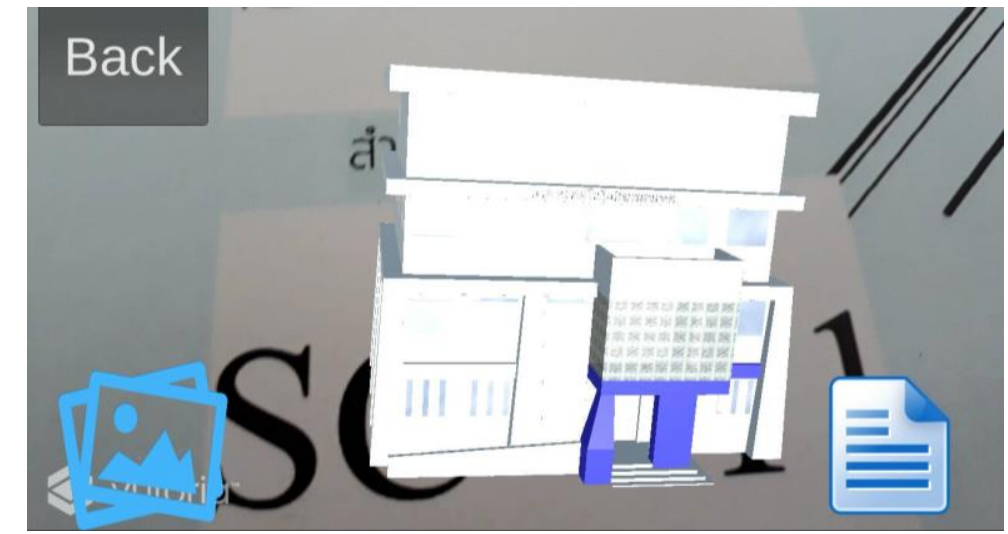

Source : Own data 
Figure 3 Information Technology project with augmented reality for tourist attraction

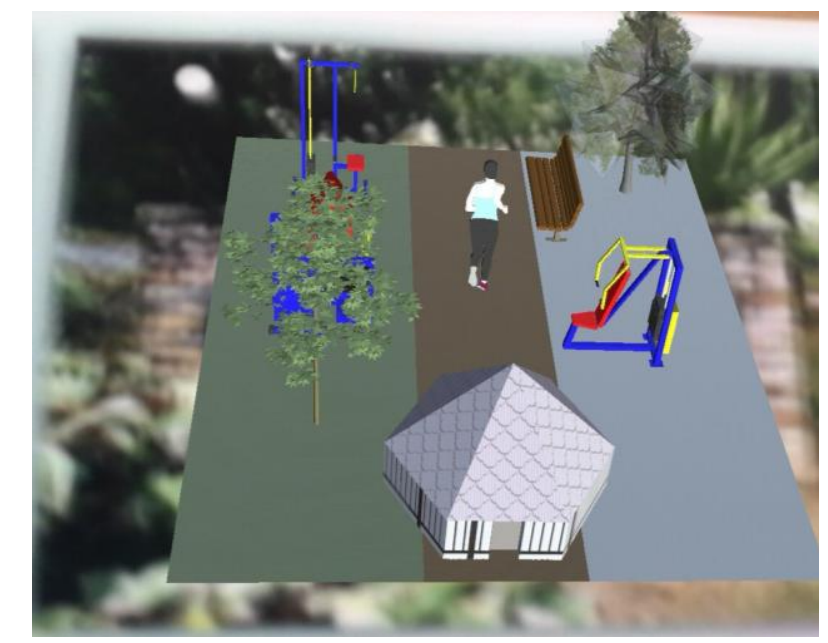

Source : Own data

Figure 2 is information technology project with augmented reality for learning building project while figure 3 is information technology project with augmented reality for tourist attraction.

\section{Conclusions}

The findings indicated that the use of instruments of learning and teaching system can design an information technology project with augmented reality model included 5 component: analysis module, design module, user interface module, implementation module and testing module. In addition, the evaluation information technology systems by 20 users revealed that the sample groups were satisfied with this content validity of system at a high level and the mean score was 4.25 and the standard deviation of users' satisfaction was 0.15 .

\section{Acknowledgements}

Thanks go to Information Technology Program, Faculty of Liberal Arts and Science, Kasetsart University, Kamphaengsaen Campus, Nakhon Pathom ,Thailand for providing facilities and tools in this study. Special thanks go to the participants for sharing their time and expertise in this study.

\section{References}

Kendall, K.E. (2005). Systems Analysis and Design. 6th ed. Pearson Prentice Hall, Upper Saddle Reiver. New Jersey.

Marakas, G.M. (2001). Systems Analysis and Design : An Active Approach. Prentice Hall. New Jersey. 